\title{
MANAGEMENT GUIDELINES FOR EVACUATION ROUTES IN AREAS PRONE TO FLOODING AND LANDSLIDES: A CASE STUDY OF THE MAE PHRONG RIVER BASIN AREA IN THAILAND
}

\author{
Nipawan Kunsuwan ${ }^{1}, *$ Bunpoat Kunsuwan $^{2}$ \\ ${ }^{1,2}$ Department of Civil Engineering, Faculty of Engineering at Kamphaeng Saen, Kasetsart University, \\ THAILAND;
}

*Corresponding Author, Received: 27 Sept. 2021, Revised: 03 Dec. 2021, Accepted: 17 Dec. 2021

\begin{abstract}
Flooding and landslides have been a significant hazard in Thailand, especially in steep areas. This study aimed to find suitable evacuation routes for future disaster prevention planning and management by the local authority appropriate to the needs of affected people living in steep areas of Uttaradit province. Evacuation routes were analyzed using the trip assignment model with the optimization technique according to the shortest path and 20 vehicles (pickup trucks) used for organizational planning. The results showed evacuation with the group would take more time than for ungrouped people by almost half an hour, but the number of vehicles could be reduced by one. In addition, for both ungrouped and grouped types, increasing the number and speed of the vehicles decreased the evacuation time by about 20 minutes if the local authorities increased the number of existing vehicles from 20 to 30 and allowed a vehicle speed of 30 kilometers per hour. The information for evacuation management and period obtained in each simulation from this research would be beneficial for determining evacuation notification periods. The results could be used as guidelines for other local authority plans in steep or similar risk areas where efficient evacuation is necessary due to flooding and landslides. Important requirements can be added to facilitate evacuation, such as the road capacity during the evacuation, an alternative route during flooding even and a plan for clearing roads affected by landslides.
\end{abstract}

Keywords: Evacuation, Flooding, Landslides, Vehicle routing, Trip assignment model

\section{INTRODUCTION}

Thailand is being affected by more frequent and large flood disasters. In addition to flooding, heavy rain that occurs on steep slopes can cause landslides. The landslide hazard map shows that Uttaradit province has a large area with a high chance of landslides in mountainous areas, especially in Laplae district [1]. This province also has a history of flood disasters and landslides, such as on May 23, 2005 , that resulted in the deaths of 83 people, 33 people missing, 673 houses damaged and $771 \mathrm{~km}^{2}$ of the agricultural area damaged, representing a total damage cost of THB 308.6 million.

Generally, to assess the effectiveness of disaster risk management in areas prone to landslides, the good characteristics of disaster risk management are proposed such as participation, collaboration, information, decision making, communication, leadership, and shared resources. In the part of preparing for life-threatening flooding, several methods have been applied to detect a hazard with the adoption of the early warning system, followed by communication of a sufficient time to take shelter, evacuate, or any action earlier than a disaster [2-4]. Some of the common methods used to study flood and landslide hazard assessment are remote sensing, statistical analyses, deterministic or probabilistic methods that involve the analysis of specific slopes based on geotechnical engineering model, GIS-based Multi-Criteria Decision Analysis. The development of models for evacuation planning and preparing evacuation routes could contribute to reduce human and property losses and also improve emergency operation [5-7].

Vehicle routing can be analyzed in a variety of ways, whether it is a comparison of each route to find the most useful route or using advanced mathematical models that can put conditions into the analysis. A mathematical model was developed for truck cargo transportation (Vehicle Routing Problem, VRP) to deliver goods to the hands of many customers with various objective functions [8-13]. These models have continued to progress until they have been applied in disaster management and planning.

The study of emergency transportation problems during natural disasters, such as transport of rescue equipment, medical assistance team transportation, transport of food, and other 
sustenance, can make use of mathematical modeling to pick up items within a limited time during a disaster [14]. For evacuation planning, the location, the boundary service area, and the evacuation route are the most significant issues correlated to shelter preparation [15]. A mathematical model was used to solve the shortest evacuation routes for the affected people in the flood-affected area, where it was determined that the use of each vehicle was the most worthwhile, each vehicle must carry as many evacuees as possible in each run, with analysis divided into multiple routes and the population calculated for each evacuation route [16]. Such a mathematical model can be used in conjunction with a geographical information system to indicate location for assistance, to minimize transport distances for supplies and to sustain affected people during flooding events [17]. Heuristic modeling analysis and reliability analysis modeling has been used to plan medical transportation in disaster-affected areas $[18,19]$.

Wannasiri [20] proposed two models to solve transportation problems by using linear programming for the analysis of mathematical models to identify the route that minimized the total time and cost spent on transport. Nakanishi et al., [21] developed an evacuation model based on the shortest paths by consideration of the relative usage of shelters; the demographics; the individual and overall times to evacuate; and the number of people who remain to shelter in a high-risk area. The transportation simulation was applied to support short-notice and evacuation planning during a tsunami evacuation by excluding the real-world measuremetns of vehicle demand and flow [22]. Agent-based modeling was applied to simulate the evacuation behavior of residents focused on the older people with various hypothetical situations such as the use of cars and walking, the capacity of the road network, and the location of shelters [23]. The virtual reality experiments were used to propose public interventions for promoting evacuation by specifying the recommended time for evacuation [24].

\section{RESEARCH SIGNIFICANCE}

This research aimed to analyze the patterns of evacuation routes in flooding and landslide-prone areas by using the trip assignment model with the shortest path technique. The pattern of evacuation was divided into two types: 1) ungrouped, where the vehicles will only pick up the evacuees at one assembly point in one trip; and 2) grouped, where the vehicles are assigned to pick up the evacuees who are waiting at assembly points located nearby. Various cases were considered, such as increasing the number of vehicles and the vehicle speed and were compared in terms of evacuation time. The results from the research can apply as guidelines for the local authority regarding assembly points and shelter, making appropriate arrangements for evacuation vehicles and allowing for the maximum warning period prior to the evacuation process, which should ensure the safety and efficient evacuation of the affected people in the pre-disaster management period.

\section{METHODS}

\subsection{Study Area}

The Mae Phrong river basin area, Mae Phun Subdistrict, Laplae District, Uttaradit Province is located in lower northern Thailand. The climate of Uttaradit Province is Tropical savannah climate: Aw. Rain in the area is caused by the influence of the southwest monsoon.

The population and number of households in Mae Phrong (the study area) in 2018 were 3,276 people divided into 1,660 males and 1,616 females with a total of 1,346 households. People in the area mostly engaged in agriculture (horticulture and agroforestry). The general topography is forests and mountains. There are plains in the central and southern parts of the area, with important waterways (Mae Phun and Mae Phrong canals) that supply water to irrigate crops as a major economic activity. Local routing is via a small road network within the community. There is a two-way road (width 3-5 meters) without road shoulders and some parts of road are flat while other parts are very steep with the latter roads requiring caution and skill while driving.

\subsection{Data Collection}

\subsubsection{Evacuation plan}

Information on the evacuation plan was obtained from the local authorities and covered the evacuation process, the number of vehicles ready for use in an evacuation, places for use as assembly points and shelter [25] and their capacities based on international capacity and allocated living space standards in the shelters [26]. The route network in the study area was derived from maps.

In addition, analysis results obtained from a previous study in this area had indentified key factors contributing to the choice of preferring vehicle prepared by the local authorities because of

the following factors: safety while evacuating, convenience of vehicle accessibility, quick access 
to shelters, evacuating people in the same family together, an uncomplicated evacuation, and a short evacuation time and time to get to the assembly point from dwellings [27]. Therefore, these factors were used in the development of the current route model along with considering the evacuation plans of the local relevant authority, namely Department of disaster prevention and mitigation (DDPM) 2017. The model was based on 20 pickup trucks (fourwheel drive) that could each evacuate 10 people and their safe vehicle speed during evacuation was 30 kilometers per hour. According to [28], the giving rate for getting in and out of the heavy truck is at 60 seconds per person; however, in this research, 30 seconds per person was assumed as that rate is more appropriate for a light vehicle. Furthermore, for the base case, the period of each evacuation for each group was set to not exceed 3 hours after evacuation notification

\subsubsection{Number of Evacuees}

The prediction of evacuees was analyzed based on two sets data; 1) the percentage of respondents would like to evacuate to the shelter immediately after receiving an evacuation notification (84.55\%) [27] and 2) the number of affected people living in the hazard-prone area that was predicted by considering two factors affecting the hazard-prone area, namely flooding and landslides. A spatial analytical technique was applied to identify affected houses and using different buffer offsets from the river (25 meters, 50 meters, and 100 meters) and varying distances from the susceptible landslide sites (50 meters, 100 meters, 150 meters, and 200 meters). The results of this analysis that identified the locations of houses at risk are shown in (Fig.1). Five villages were presented.

The percentage of houses at risk was used to verify the reliability of the data for further use based on 3 sources: 1) records of flood disaster and landslides in 2006; 2) interviews with relevant local authorities, the community leaders of each village and villagers living in the area; and 3) household analysis in risk area based on the 2012 data of those affected by landslides and flooding in the Mae Phrong Basin [29]. All data were analyzed one-way ANOVA and determining hypotheses for testing. The tests found that the F value was equal to 0.496 and the Sig. value was equal to 0.690 which was greater than 0.05 , so it was concluded that the percentage of houses at risk was not different from the compared data set. Therefore, the percentage of houses at risk could be used to estimate the number of affected people, and the number of evacuees was then predicted by multiplying by $84.55 \%$ (Table 1 ).

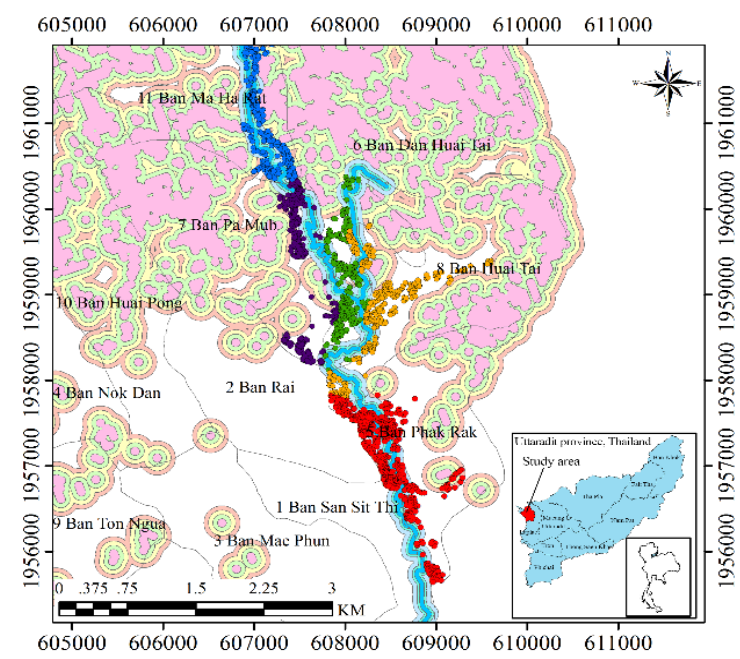

Legend

$$
\begin{aligned}
& \text { - Houses: Village } 5 \\
& \text { - Houses: Village } 6 \\
& \text { - Houses: Village } 7 \\
& \text { - Houses: Village } 8 \\
& \text { - Houses: Village } 11 \\
& \text { - Boundary line }
\end{aligned}
$$

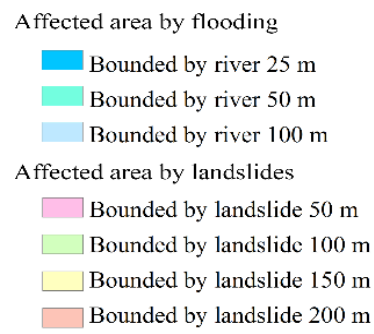

Fig.1 Predicted Locations of Affected Houses in Flooding and Landslides-Prone Area

Table 1 Predicted numbers of affected people and evacuees

\begin{tabular}{ccc}
\hline $\begin{array}{c}\text { Village } \\
\text { number }\end{array}$ & $\begin{array}{c}\text { Number of } \\
\text { affected people }\end{array}$ & $\begin{array}{c}\text { Number of } \\
\text { evacuees }\end{array}$ \\
\hline 5 & 353 & 298 \\
6 & 272 & 230 \\
7 & 369 & 312 \\
8 & 235 & 199 \\
11 & 243 & 206 \\
\hline Total & 1,472 & 1,245 \\
\hline
\end{tabular}

\subsubsection{Model of evacuation routes}

The collected data were used to determine the points of origin (assembly points) and destinations (shelters) based on the route network. The locations of the 10 assembly points (A1-A10) each with the required number of evacuees (total 1,245 persons) was determined by the distance people had to travel from their houses in each village to the nearest assembly point to wait for evacuation to a shelter (S1-S10) according to the capacity of each shelter. Fig. 2 shows the location of assembly points and shelters in the route network. 


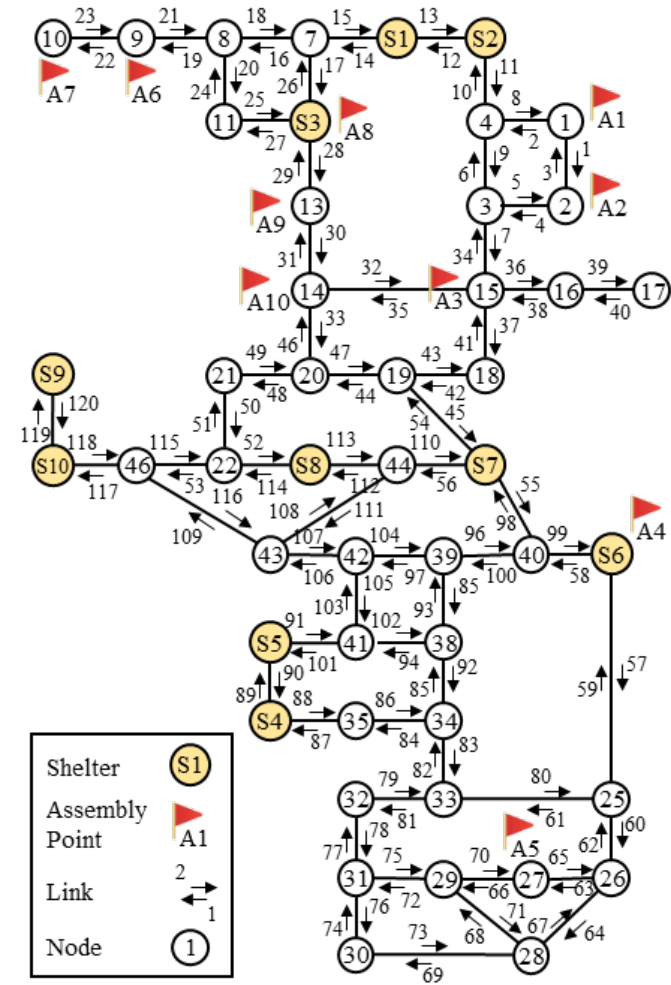

Fig. 2 Location of Assembly Points and Shelters in the Route Network

In this regard, the evacuation options were by various routes (paths) from the point of origin to the destination point, with each path including links and nodes. In total, there were 445 routes. All data were utilized to develop the evacuation route model.

The evacuation route model was designed based on the all-or-nothing assignment (AON) method, accompanied by optimization techniques. In the optimal solution, the objective function of the model was set to the route that provides the lowest total expected evacuation distance from the assembly point to the shelter. There were three important constraints applied: 1) the evacuees will travel on the designated link on each path; 2) all evacuees at any assembly point must be evacuated to shelters; and 3) the capacity of each shelter must be defined.

The model was assigned with every vehicle starting a journey from the shelter and then traveling to pick up evacuees at each assembly point as defined. There were two types of analysis: ungrouped type and grouped type. Each type differed according to the process of picking up the evacuees at several nodes. For example (Fig.2) consider the evacuation routes between $\mathrm{S} 1$ and assembly points A1, A2, and A6, where A1 and A2 are in the same direction. In the ungrouped type analysis, the vehicles are assigned to pick up all 3 nodes, with one of the vehicles picking up at only one node to the shelter until there are no more evacuees. With the grouped type, nodes are grouped in the same area, so the evacuation routes can be divided into two groups based on the location of nodes. In the first group, the evacuees are taken from only one point at node A6 to shelter. In the second group, the vehicle is assigned to pick up the evacuees at node $\mathrm{A} 1$ and $\mathrm{A} 2$ respectively. These two travels routes will continue until there are no more evacuees

\section{RESULTS AND DISCUSSIONS}

\subsection{Evacuation Route Results for Ungrouped and Grouped Types}

The optimal values of the optimization for the ungrouped and grouped types were 1,484,886 people-meter and 1,693,937 people-meter, respectively, and there were 59 and 41 round trips, respectively. However, 6 shelters were required (S1 S2 S3 S6 S7, and S8) for both types. Other details are shown in Table 2-5, such as evacuation route, vehicle used for each route, and evacuation time (travel time plus time taken in getting in/out of vehicle).

Table 2 Results of evacuation routes for ungrouped type

\begin{tabular}{|c|c|c|}
\hline $\begin{array}{l}\text { Shelter } \\
\text { (capacity) }\end{array}$ & $\begin{array}{c}\text { Assembly } \\
\text { point } \\
\text { (evacuees) }\end{array}$ & $\begin{array}{l}\text { Evacuation route } \\
\text { (link-link) }\end{array}$ \\
\hline \multirow[t]{3}{*}{ S1 (222) } & A1 (82) & $13-11-8-2-10-12$ \\
\hline & A2 (14) & $13-11-8-1-3-2-10-12$ \\
\hline & A6 (126) & $14-16-19-21-18-15$ \\
\hline S2 (28) & A2 (28) & 11-8-1-3-2-10 \\
\hline \multirow[t]{3}{*}{ S3 (229) } & A6 (46) & 26-16-19-21-18-17 \\
\hline & A7 (34) & $\begin{array}{c}26-16-19-22-23-21-18- \\
17\end{array}$ \\
\hline & A8 (149) & - \\
\hline \multirow[t]{2}{*}{ S6 (405) } & A4 (158) & - \\
\hline & A5 (140) & $57-60-63-65-62-59$ \\
\hline \multirow[t]{2}{*}{ S7 (235) } & A2 (106) & $\begin{array}{c}54-43-41-34-5-4-7-37- \\
42-45\end{array}$ \\
\hline & A3 (129) & $54-43-41-37-42-45$ \\
\hline \multirow[t]{3}{*}{ S8 (366) } & A3 (70) & $\begin{array}{c}113-110-54-43-41-37- \\
42-45-56-112\end{array}$ \\
\hline & A9 (111) & $\begin{array}{c}114-51-49-46-31-30-33- \\
48-50-52\end{array}$ \\
\hline & A10 (52) & $\begin{array}{c}114-51-49-46-33-48-50- \\
52\end{array}$ \\
\hline \multicolumn{2}{|c|}{ Total routes } & 12 \\
\hline
\end{tabular}


Table 3 Results of evacuation time for ungrouped type

\begin{tabular}{ccc}
\hline $\begin{array}{c}\text { Shelter- } \\
\text { Assembly point }\end{array}$ & $\begin{array}{c}\text { Vehicle } \\
\text { used }\end{array}$ & $\begin{array}{c}\text { Evacuation time } \\
\text { (minute) }\end{array}$ \\
\hline S1-A1 & 2 & 49.50 \\
S1-A2 & 1 & 12.80 \\
S1-A6 & 2 & 118.80 \\
S2-A2 & 1 & 20.90 \\
S3-A6 & 1 & 45.00 \\
S3-A7 & 1 & 58.00 \\
S3-A8 & - & - \\
S6-A4 & - & - \\
S6-A5 & 2 & 116.70 \\
S7-A2 & 2 & 121.50 \\
S7-A3 & 2 & 104.70 \\
S8-A3 & 2 & 66.90 \\
S8-A9 & 2 & 146.00 \\
S8-A10 & 2 & 51.50 \\
\hline
\end{tabular}

\begin{tabular}{ccc}
\hline Total vehicles & 20 & 65.16 (Average) \\
\hline Note: *maximum time used in evacuation route of $S 8-A 9$ for
\end{tabular}
ungrouped type.

Table 4 Results of evacuation routes for grouped type

\begin{tabular}{ccc}
\hline $\begin{array}{c}\text { Shelter } \\
\text { (capacity) }\end{array}$ & $\begin{array}{c}\text { Assembly } \\
\text { point } \\
\text { (evacuees) }\end{array}$ & $\begin{array}{c}\text { Evacuation route } \\
\text { (link-link) }\end{array}$ \\
\hline S1 (22) & A1 A2 (96) & $\begin{array}{c}13-11-8-1-3-2-10- \\
12\end{array}$ \\
& A6 (126) & $14-16-19-21-18-15$ \\
S2 (28) & A2 (28) & $11-8-1-3-2-10$ \\
S3 (229) & A6A7 (80) & $26-16-19-22-23-21-$ \\
& A8 (149) & $18-17$ \\
S6 (405) & A4 (158) & - \\
& A5 (140) & $57-60-63-65-62-59$ \\
S7 (235) & A2A3 (235) & $54-43-41-34-5-4-7-$ \\
& & $37-42-45$ \\
S8 (366) & A3 (70) & $113-110-54-43-41-$ \\
& & $37-42-45-56-112$ \\
& A9A10 (163) & $114-51-49-46-31-$ \\
& & $30-33-48-50-52$ \\
\hline
\end{tabular}

In the ungrouped type option, Table 2 and Table 3 showed the results of evacuation routes and evacuation time respectively, 12 routes were proposed and 20 vehicles would be used for evacuation. For example, one evacuation route between S2-A2 was established using one vehicle and taking a total evacuation time of 20.90 minutes.
In the viewpoint of the longest evacuation period, it took place on route S8-A9, which took 146 minutes.

Table 5 Results of evacuation time for grouped type

\begin{tabular}{ccc}
\hline $\begin{array}{c}\text { Shelter - } \\
\text { Assembly point }\end{array}$ & $\begin{array}{c}\text { Vehicle } \\
\text { used }\end{array}$ & $\begin{array}{c}\text { Evacuation time } \\
\text { (minute) }\end{array}$ \\
\hline S1-A1A2 & 2 & 62.50 \\
S1-A6 & 2 & 118.80 \\
S2-A2 & 1 & 20.90 \\
S3-A6A7 & 2 & 81.00 \\
S3-A8 & - & - \\
S6-A4 & - & - \\
S6-A5 & 2 & 116.60 \\
S7-A2A3 & 5 & 174.00 \\
S8-A3 & 2 & 66.90 \\
S8-A9A10 & 3 & 172.00 \\
\hline Total vehicles & 19 & 58.06 (Average) \\
\hline Note: *maximum time used in evacuation route of S7-A2A3 for \\
grouped type.
\end{tabular}

In the grouped type option, Table 4 and Table 5 showed that 8 routes were suggested and 19 vehicles would be used. The longest evacuation period for this option (174 minutes) was presented in S7-A3A3 using 5 vehicles.

In addition, the results were compared between the two types and the evacuation times were different (Table 6). For example, the transported routes in the ungrouped type which were S7-A2-S7 and S7-A3-S7 presented the evacuation time as 121.5 minutes and 104.7 minutes respectively. It was found that they took less time to evacuate comparing to the grouped option by focusing on the same original-destination, S7-A2-A3-S7.

Table 6 Comparison of evacuation time between ungrouped and grouped types

\begin{tabular}{|c|c|c|c|}
\hline \multirow{2}{*}{$\begin{array}{c}\text { Shelter- } \\
\text { Assembly } \\
\text { point }\end{array}$} & \multicolumn{2}{|c|}{ Evacuation time } & \multirow{2}{*}{$\begin{array}{c}\text { Time } \\
\text { difference }^{\mathrm{b}} \\
\text { (minutes) }^{\text {b }}\end{array}$} \\
\hline & $\begin{array}{l}\text { ungrouped } \\
\text { type }^{a}\end{array}$ & $\begin{array}{l}\text { grouped } \\
\text { type }\end{array}$ & \\
\hline $\mathrm{S} 1-\mathrm{A} 1, \mathrm{~A} 2$ & $\underline{49.5}, 12.8$ & 62.5 & 13 \\
\hline S3-A6,A7 & $45.0, \underline{58.0}$ & 81.1 & 23 \\
\hline $\mathrm{S} 7-\mathrm{A} 2, \mathrm{~A} 3$ & $\underline{121.5}, 104.7$ & 174 & 52.5 \\
\hline S8-A9,A10 & $146.0,51.5$ & 172 & 26.0 \\
\hline
\end{tabular}

The results of routing showed some different evacuation characteristics

- The ungrouped type had lower optimal 
values than the grouped type since the ungrouped type used a lower total evacuation distance than the grouped type.

- The maximum number of evacuees per route in the ungrouped type was less than that for the grouped type because in the grouped type, some paths had been arranged for evacuees to be picked up based on assembly points in the same direction for more than one gathering point. Furthermore, an increasing number of evacuees per path resulted in an increased evacuation time

- In ungrouped type option, all 20 vehicles must be used according to the plan by the local authorities, resulting in evacuation time of 146 minutes. For the grouped type, the number of vehicles could be reduced to 19 , but evacuation time was the longest (174 minutes) by about 28 minutes compared to the ungrouped type. The model clearly showed that the ungrouped type evacuation used one more vehicle but took less overall time for evacuation than for the grouped type.

In addition, the ungrouped type had lower total evacuation distance than that for the grouped type by about 35 kilometers. However, each management type had different advantages and that can be analyzed as follows:

- The ungrouped type took less time to evacuate resulting in increased safety and lower fuel costs because of shorter total distance. From the management viewpoint, the less the number of evacuees per route, the more effective the management will be

- The grouped type result involve fewer vehicles and drivers. From the management point of view, the fewer the number of evacuation routes, the more effective the management will be.

\subsection{Effect of Evacuation Time from Number and Speed of Vehicles}

In the previous part, the base case model was analyzed using 20 vehicles and a speed of 30 kilometers per hour according to the plan developed by the local authorities. The times used for evacuation in the ungrouped and grouped types in the base case were 2.03 hours and 2.87 hours, respectively. In this part, the number of vehicles used for evacuation and speed were set in various scenarios to compare evacuation times. There were 3 cases with differing numbers of vehicles: 1) one vehicle per route (12 vehicles in ungrouped type and 9 vehicles in grouped type); 2) 20 vehicles; and 3) 30 vehicles. Vehicle speed was divided into 3 levels: 20, 30, and 40 kilometers per hour. Therefore, 9 scenarios were analyzed and summarized in terms of the longest evacuation time. The results of ungrouped and grouped types are presented in Fig.3 and Fig.4, respectively.

In the ungrouped type, reducing the number of vehicles from 20 to 12 increased the evacuation time (from 2.03 hours to 6.07 hour) for the case using a speed of 20 kilometers per hour, which was an increase of almost 3 times from the base case. However, adding up to 30 vehicles accompanied with changing their speed to 40 kilometers, reduced the evacuation time to 1.42 hours.

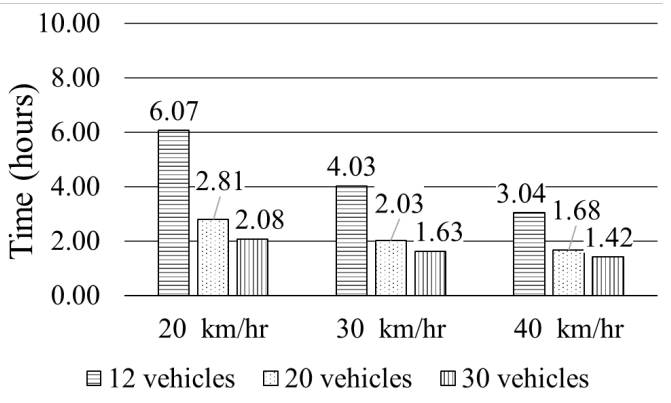

3 Evacuation time of paired situations for ungrouped type

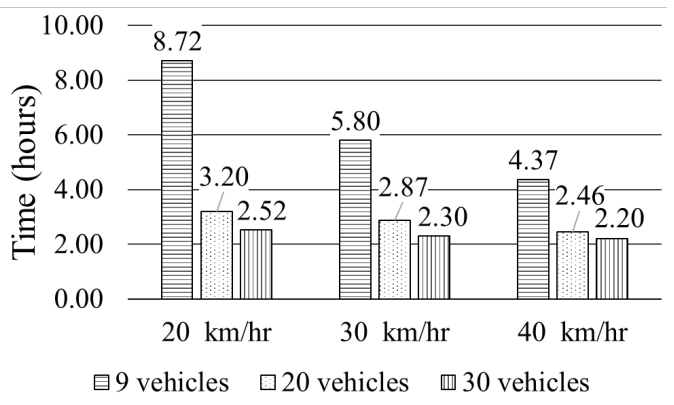

Fig.4 Evacuation time of paired situations for grouped type

In the grouped type, reducing the number of vehicles from 20 to 9 resulted in an additional evacuation times for all three speeds of 8.72 hours, 5.80 hours, and 4.37 hours, respectively. Adding up to 30 vehicles accompanied with changing their speed to 40 kilometers reduced the evacuation time to 2.20 hours, which was longer than for the ungrouped type.

It could be revealed that where 30 vehicles were used, the evacuation time could be reduced by approximately 23-34 minutes. Furthermore, the evacuation time was reduced to applaximately 20 minutes if the vehicle speed was increased to 40 kilometers per hour and 20 vehicles were used. 


\section{CONCLUSION}

\subsection{Analytical results}

Uttaradit Province has a large area with a high chance of landslides in mountainous areas and flash flooding occurred in some parts of the area. Mea Phrong river basin area is the study area in Uttardit Province, which is located in lower northern Thailand. The development of models for evacuation planning and preparing evacuation routes could contribute to reduce human and property losses and also improve emergency operation.

This research developed evacuation routing models with an objective function to assess the shortest total route distances. The pattern of evacuation was divided into two types: ungrouped and grouped types. The network routed was considered together with 10 assembly points and various shelters. The results of the study showed that the 1,245 immediate evacuees would be tranported to 6 shelters. The times used for evacuation in the ungrouped and grouped types in the base case were 2.03 hours and 2.87 hours, respectively. It could be suggested to the local authorities that the evacuation time would not exceed 3 hours if they used 20 vehicles and a vehicle speed 30 kilometers per hour as the base case in this research, regardless of which group type was selected. However, adding up to 30 vehicles accompanied with changing their speed to 40 kilometers in the ungrouped and grouped types, reduced the evacuation time to 1.42 hours and 2.20 hours, respectively. It is possible to use the longest evacuation time to determine the appropriateness of the evacuation notification period to allow time for preparation.

It could be said that the results from this research could apply as guidelines for making appropriate arrangements for evacuation vehicles and allowing for the maximum warning period prior to the evacuation process.

\subsection{Recommendation}

This research presents practical guidelines for local authorities to apply in the development of evacuation plans that are effective and consistent with the needs of the evacuees. Therefore, after a new evacuation plan has been developed, it may be necessary provide information to local villagers so they can make a suitable choice of vehicle that is supported by the local authorities. For future study, other important requirements can be added to facilitate evacuation, such as the road capacity during evacuation, an alternative route during flooding even and a plan for clearing roads affected by landslides. In addition, the analytical thinking process in the research should allow the study to be extended to other research areas with similar characteristics. The development of a successful evacuation plan depends on the potential and limitations of each local authority and the community.

\section{ACKNOWLEDGMENTS}

Financial support was received from the Department of Engineering, Faculty of Engineering at Kamphaeng Saen, Kasetsart University, Thailand In addition, the authors would like to express their gratitude to Mr Damnern Chiangpun, a volunteer in the landslide alert network from Ban Phamub, to $\mathrm{Mr}$ Somporn Khanpingpud, chief of the Strategy and Management Subdivision at the Disaster Prevention and Mitigation Office of Uttaradit, and to $\mathrm{Mr}$ Thanawan Phiophuead.

\section{REFERENCES}

[1] Department of Mineral Resource, Landslides Prone Area Report, Mae Phun Subdistrict, Laplae District, Uttaradit Province, Thailand, 2013.

[2] Zhou L., Wu X., Xu Z., and Fujita H., Emergency decision making for natural disasters: an overview, Int. J. Disaster Risk Reduct, 27, 2018, pp.567-576.

[3] Alam E., and Ray-Bennett N.S., Disaster risk governance for district-level landslide risk management in Bangladesh, International Journal of Disaster Risk Reduction, 59, 2021, pp.1-13.

[4] Shrestha M.S., Gurung M.B, Khadgi V.R. Wagle N., Banarjee S., Sherchan U., Parajuli B., and Mishra A., The last mile: Flood risk communication for better preparedness in Nepal, International Journal of Disaster Risk Reduction 56, 2021, pp.1-12.

[5] Department of Disaster Prevention and Mitigation, Disaster Risk Reduction, 3rd ed. Work Printing Company Limited Publisher, 2016, pp. 41-45

[6] Nakanishi H., and Black J., Implicit and explicit knowledge in flood evacuations with a case study of Takamatsu, Japan, International Journal of Disaster Risk Reduction 28, 2018, pp.788-797.

[7] Rahman M., Chen N., Islam M.M., Dewan A., Pourghasemi H.R., Washakh R.M.A., Nepal N., Tian S., Faiz H., and Alam M., Ahmed N., Location-allocation modeling for emergency evacuation planning with GIS and remote sensing: A case study of Northeast Bangladesh, 
Geoscience Frontiers 12, 2021, pp. 1-17.

[8] Toth P. and Vigo D., Models, Relaxations and Exact Approaches for the Capacitated Vehicle Routing Problem, Discrete Applied Mathematics, 123(1-3), 2002, pp.487-512.

[9] Qureshi A.G., Taniguchi E. and Yamada T., An Exact Solution Approach for Vehicle Routing and Scheduling Problems with Soft Time Windows, Transportation Research Part E: Logistics and Transportation Review, Vol. 45, Issue 6, 2009, pp. 960-977.

[10] Spliet R. and Desaulniers G., The Discrete Time Window Assignment Vehicle Routing Problem, European Journal of Operational Research, Vol. 244, Issue 2, 2015, pp. 379-391.

[11] Meechaiyo B. and Sangsrichan C., Developing Transportation System Strategic Plan for Sustainable Community Development: Naresuan University Case Study, Naresuan University Engineering Journal, Vol.14, No.2, July-December 2019, pp. 1-13.

[12] Molina J.C., Salmeron J.L., Eguia I., and Racero J., The heterogeneous vehicle routing problem with time windows and a limited number of resources, Engineering Applications of Artificial Intelligence 94, 2020, pp. 1-15.

[13]Brunner C., Giesen R., Klapp M.A., and Florez-Calderon L., Vehicle routing problem with steep roads, Transportation Research Part A 151, 2021, pp. 1-17.

[14]Özdamar L., Ekinci E. and Küçükyazici B., Emergency Logistics Planning in Natural Disasters, Annals of operations research, Vol. 129, Issue 1-4, 2004, pp. 217-245.

[15] Hu F., Yang S., Hu X., and Wang W., Integrated optimization for shelter service area demarcation and evacuation route planning by a ripple-spreading algorithm, International Journal of Disaster Risk Reduction 24, 2017, pp. 539-548.

[16] Sri-Uta S., Thongkhaw A., Sittiwanchai T. and Yodpijit N., Preparing Evacuation Routing for Regional Flooding in Thailand: A Case Study of Banlambed, Tamnan, Muang, Phatthalung, IE Network Conference, 2012, pp. 83-88.

[17] Chang M.-S., Tseng Y.-L. and Chen J.-W., A Scenario Planning Approach for the Flood Emergency Logistics Preparation Problem under Uncertainty, Transportation Research Part E: Logistics and Transportation Review, Vol. 43, Issue 6, 2007, pp. 737-754.

[18] Hirunamornkun J. and Sangsawang O., Routing Design to Transport Medical Supplies during Flood-Case Study: Bangkruai, Nonthaburi, Thai
VCML Journal, Vol. 5, No.2, 2012, pp. 77-83.

[19] Koike N. and Kurahashi S., An Evaluation Model of Medical Transport with Tsunami Early Warning System, International Journal of GEOMATE, Vol.9, No.2, 2015, pp.1447-1453.

[20] Wannasiri W, Vehicle Routing Problem for Humanitarian Logistics, Master Thesis Report, Graduate School of Management and Innovation, King Mongkut's University of Technology Thonburi, 2015.

[21] Nakanishi H., Wise S., Suenaga Y., and Manley E., Simulating emergencies with transport outcomes Sim (SETOSim): Application of an agent-based decision support tool to community evacuation planning, International Journal of Disaster Risk Reduction 49, 2020, pp.1-21.

[22] Wood N., Henry K., and Peters J., Influence of demand and capacity in transportation simulations of short-notice, distant-tsunami evacuations, Transportation Research Interdisciplinary Perspectives 7, 2020, pp.2-14.

[23] Nakanishi R., Black J., and Suenaga Y., Investigating the flood evacuation behavior of older people: A case study of a rural town in Japan, Research in Transportation Business \& Management 30, 2019, pp.1-14.

[24] Fujimi T., and Fujimura K., Testing public interventions for flash flood evacuation through environmental and social cues: The merit of virtual reality experiments, International Journal of Disaster Risk Reduction 50, 2020, pp.1-11.

[25] Department of Disaster and Mitigation, Ministry of Interior, K4Flood Shelter Management Guideline, 2011.

[26] The International Organization for Migration and The United Nations High Commissioner for Refugees, 2010.

[27] Phiophuead T. and Kunsuwan N., Logistic Regression Analysis of Factors Affecting Travel Mode Choice for Disaster Evacuation, Engineering Journal, 23(6), 2019, pp.399-417.

[28] Suttijumnong P. and Chanta S., Vehicle Routing for Flood Evacuation by Considering Different Types of Victims, The Journal of KMUTNB, Vol.27, No.2, 2017, pp.289-302.

[29] Chutima, M., Alongkorn, I., and Onanong, P., Mae Prong Watershed Areas, Mae Poon Subdistrict, Laplae District, Uttaradit Province, Journal of Social Sciences Srinakharinwirot University, Vol.18, 2015, pp.40-50.

Copyright (C) Int. J. of GEOMATE All rights reserved, including making copies unless permission is obtained from the copyright proprietors 